Article

\title{
Study on Demulsification-Flocculation Mechanism of Oil-Water Emulsion in Produced Water from Alkali/Surfactant/Polymer Flooding
}

\author{
Bin Huang ${ }^{1}$, Xiaohui $\mathrm{Li}^{1}{ }^{1}$, Wei Zhang ${ }^{2}$, Cheng Fu ${ }^{1,3 * *}$, Ying Wang ${ }^{4}$ and Siqiang Fu ${ }^{5}$ \\ 1 The Key Laboratory of Enhanced Oil and Gas Recovery of Educational Ministry, \\ Northeast Petroleum University, Daqing 163318, China; huangbin111@163.com (B.H.); \\ lixiaohuibusiness@163.com (X.L.) \\ 2 Shandong Key Laboratory of Oil-Gas Storage and Transportation Safety, College of Pipeline and Civil \\ Engineering, China University of Petroleum, Qingdao 266580, China; 15776541967@163.com \\ 3 Post-Doctoral Research Station of Daqing Oilfield, Daqing 163458, China \\ 4 Aramco Asia, Beijing 100102, China; ying.wang.1@aramcoasia.com \\ 5 No. 1 Oil Production Plant in Daqing Oilfield, Daqing 163001, China; fusiqiang@petrochina.com.cn \\ * Correspondence: cheng_fu111@163.com; Tel.: +86-158-4616-2836
}

Received: 18 December 2018; Accepted: 22 February 2019; Published: 28 February 2019

\begin{abstract}
The issue of pipeline scaling and oil-water separation caused by treating produced water in Alkali/Surfactant/Polymer (ASP) flooding greatly limits the wide use of ASP flooding technology. Therefore, this study of the demulsification-flocculation mechanism of oil-water emulsion in ASP flooding produced water is of great importance for ASP produced water treatment and its application. In this paper, the demulsification-flocculation mechanism of produced water is studied by simulating the changes in oil-water interfacial tension, Zeta potential and the size of oil droplets of produced water with an added demulsifier or flocculent by laboratory experiments. The results show that the demulsifier molecules can be adsorbed onto the oil droplets and replace the surfactant absorbed on the surface of oil droplets, reducing interfacial tension and weakening interfacial film strength, resulting in decreased stability of the oil droplets. The demulsifier can also neutralize the negative charge on the surface of oil droplets and reduce the electrostatic repulsion between them which will be beneficial for the accumulation of oil droplets. The flocculent after demulsification of oil droplets by charge neutralization, adsorption bridging, and sweeping all functions together. Thus, the oil droplets form aggregates and the synthetic action by the demulsifier and the flocculent causes the oil drop film to break up and oil droplet coalescence occurs to separate oil water.
\end{abstract}

Keywords: Alkali/Surfactant/Polymer flooding; produced water; oil-water emulsion; demulsification; flocculation

\section{Introduction}

After years of development, most oil fields in China have now entered the late stage of high water cut development. Daqing Oilfield was the first in the world to commercialize the technology of Alkali/Surfactant/Polymer (ASP) flooding in 2014. ASP flooding has proved to be effective in improving oil recovery by $20 \%$ compared with water flooding. It has seen industrial application in the Daqing Oilfield [1].

Although ASP flooding technology can greatly increase field output and oil recovery compared with water flooding, it also brings severe challenges to oilfield surface engineering. Compared with the new methods of development with less pollution such as microbial flooding and nano-fluid flooding [2-4], pipeline scaling is a serious issue causing pipes to become easily blocked due to 
the existence of oil displacement agents. It has a serious influence on production and even safety accidents [5-7]. At the same time, the existence of residual chemical agents in the ASP flooding produced water will lead to complications in the produced water [8,9]. The produced water has a high salinity, high degree of emulsification, strong interfacial film strength and high content of small oil droplets [10-12]. As a result, it is difficult to separate oil and water which greatly limits commercialized ASP flooding technology.

In order to form an ultra-low oil-water interfacial tension during the ASP flooding process, a surfactant was added. The flow with low interfacial tension can pass easily through the porous medium, resulting in an improvement in oil recovery [13]. However, the addition of a surfactant not only enhances oil recovery, but also inevitably causes the serious emulsification of the ASP flooding produced water, which increases the stability of the oil droplets, resulting in difficulty treating the produced water.

Adequate mixing and the presence of a surface-active agent are two vital factors that lead to the emulsion formation when the oil and water phases are brought together [14]. The oil droplets rupture under the action of viscous shear stress. The alkali and surfactant reduce the interfacial tension greatly, which reduces the stability of the oil droplets. The polymers increase the emulsion stability by increasing water phase viscosity, decreasing the rate of raising the oil droplets, and higher polymer concentration results in higher interfacial film strength. The alkali enhances the stability of emulsion by reacting with acidic substances in crude oil to form a surfactant. The surfactant can adsorb onto the oil-water interface, which reduces the interfacial tension and increases the strength of the interface membrane. On the one hand, the capillary force that promotes the drainage of the liquid film and the fluidity at the oil-water interface is reduced. On the other hand, the electrostatic repulsion on both sides of the liquid film is reduced. The combined effect acts as a hindrance in the coalescence of oil beads. Under the interaction of the alkali, surfactant and polymer, the system is emulsified and forms the $\mathrm{O} / \mathrm{W}$ emulsion $[15,16]$.

The emulsion in ASP flooding produced water causes difficulties in its treatment. Many conventional processes have been used to treat produced water in oilfields, including gravity separation [17], floatation [18,19], demulsification [20,21], membrane separation [22], air flotation [23], adsorptive separation [24] and biotechnology [25]. However, only a few studies have reported the treatment of produced water from ASP flooding. Deng et al. studied the influence of an oil displacement agent on the stability of oil droplets in ASP flooding water and the influence of different demulsifiers and flocculants on the stability of oil droplets [26,27]. It was found that the effect of the oil-soluble demulsifier was better than that of water-soluble demulsifier. Oil-soluble demulsifiers can reduce the oil-water interfacial tension and Zeta potential on the surface of oil droplets. Therefore, it can increase the oil droplet size and facilitate the coalescence of oil droplets. Wang et al. studied the influence of alkali, polymer and surfactant on oil-water separation of simulated produced water from ASP flooding [28]. The results showed that the simulated produced water from ASP flooding can be successfully treated using a leaching solution of alkaline white mud. Due to the significant effect of the white mud on the treatment of produced water, Gao et al. [29] further studied this phenomenon. They evaluated the efficiency of removing emulsified oil by metallic hydroxides were in-situ generated (IGMHs) from simulated ASP flooding produced water and found the oil removal rate was up to $99 \%$. They proved the economic viability of treatment process recovery of oil from oily wastewater. Zhang et al. [30] investigated the removal efficiency of PTFE film on the main pollutants of ASP produced water and proved that PTFE film also achieves a good treatment effect of produced water. Miao et al. [31] studied the effect of asphaltene on oil-water interface properties. The study showed that asphaltene aggregated to form film on the oil-water interface. The effluent velocity of the liquid film was reduced and the stability of produced water was improved.

Although these methods have a good performance in the treatment of ASP flooding produced water, they are limited to laboratory experiments and cannot be commercialized. It is difficult to achieve the reinjection standard by only using a demulsifier or flocculant alone to treat the produced water 
from ASP flooding. Therefore, we consider using a demulsification-flocculation method to improve the treatment effect of produced water. The produced water is firstly demulsified and then flocculated. In order to verify the feasibility of treatment of produced water by the demulsification-flocculation method, the demulsification-flocculation mechanism of oil-water emulsion in ASP flooding produced water must be fully understood. In this study, the effect of the demulsification-flocculation mechanism of oil-water emulsion from ASP flooding produced water was investigated with regards to interfacial tension, Zeta potential, and median size and microscopic morphology of oil droplets.

\section{Materials and Experimental Methods}

\subsection{Experimental Materials and Instruments}

Table 1 shows the experimental materials and sources used.

Table 1. Experimental drugs and sources.

\begin{tabular}{cc}
\hline Drugs & Sources \\
\hline $\mathrm{NaCl}$ & Tianjin Damao Chemical Plant \\
$\mathrm{Na}_{2} \mathrm{HCO}_{3}$ & Tianjin Yaohua Chemical Plant \\
$\mathrm{Na}_{2} \mathrm{CO}_{3}$ & Tianjin Yaohua Chemical Plant \\
$\mathrm{Na}_{2} \mathrm{SO}_{4}$ & Tianjin Yaohua Chemical Plant \\
$\mathrm{CaCl}_{2}$ & Harbin Xinda Chemical Plant \\
$\mathrm{MgCl}_{2}$ & Tianjin Fuchen Chemical Plant \\
Petroleum Ether & Shenyang W\&S Chemical Plant \\
\hline
\end{tabular}

All of the drugs above are analytical reagents.

Distilled water was used in the experiments. The crude oil had a moisture content of less than $0.5 \%$, a viscosity of $60 \mathrm{mPa} \cdot \mathrm{s}$, and a density of $860 \mathrm{~kg} / \mathrm{m}^{3}$ at a temperature of $45^{\circ} \mathrm{C}$. The crude oil was provided by No. 1 Oil Production Plant in Daqing Oilfield. The polyacrylamide, hydrolyzed polyacrylamide (HPAM), with $300 \times 10^{4}$ molecular weight and $25-30 \%$ hydrolysis degree, was from the Daqing Oilfield Production Engineering Research Institute. The surfactant with 50\% effective content was alkyl benzene sulfonate, ORS-41. This was provided by the No. 1 Oil Production Plant in Daqing Oilfield. The alkali was reagent grade $\mathrm{NaOH}$. The oil-soluble demulsifiers DYRPR-1625 and DPR-1870 and the organic flocculents cationic polyacrylamide (CPAM) and D2N-1650 provided by the No. 1 Oil Production Plant in Daqing Oilfield were used in the experiments.

Information regarding the experimental instruments is shown in Table 2.

Table 2. Experimental instruments.

\begin{tabular}{|c|c|c|c|}
\hline Purpose & Instrument Name & Types & Manufacturer \\
\hline Preparation of emulsion & Digital display disperser & IKAT25 & IKA Company \\
\hline Zeta potential & $\begin{array}{l}\text { Micro electrophoresis } \\
\text { apparatus }\end{array}$ & JS94H & $\begin{array}{l}\text { Shanghai Zhongchen Digital } \\
\text { technology equipment Co. Ltd. }\end{array}$ \\
\hline Oil droplet size distribution & $\begin{array}{l}\text { Laser particle size } \\
\text { analyzer }\end{array}$ & BT-9300H & $\begin{array}{c}\text { Dandong Better Science and } \\
\text { Technology Co. Ltd. }\end{array}$ \\
\hline Interfacial tension & Interface tension meter & XZD-5 & $\begin{array}{l}\text { Beijing Hake Experimental } \\
\text { Instrument Factory }\end{array}$ \\
\hline Temperature control & Thermostatic water bath & S501-2 & $\begin{array}{c}\text { Liaoyang Huaguang Instrument } \\
\text { Factory }\end{array}$ \\
\hline Micrographs observation & Biological microscope & IX73 & $\begin{array}{l}\text { Shanghai Puhe Biotechnology } \\
\text { Co. Ltd. }\end{array}$ \\
\hline Weigh & Electronic balance & BS210S & $\begin{array}{c}\text { Sartorius scientific Instruments } \\
\text { Co. Ltd. }\end{array}$ \\
\hline Quantitative transfer liquid & Micropipette & Eppendorf & Eppendorf China Co. Ltd. \\
\hline
\end{tabular}




\subsection{Experimental Procedure}

Preparation of simulated mineralized water. According to the underground water and discharge water qualities in the Daqing oilfield, mineralized water was prepared, and the salts contained in the mineralized water were as follows (mg/L): $\mathrm{NaCl} 1523, \mathrm{NaHCO}_{3} 2820, \mathrm{Na}_{2} \mathrm{CO}_{3}$ 168.7, $\mathrm{Na}_{2} \mathrm{SO}_{4} 10.5$, $\mathrm{CaCl}_{2} 56.9, \mathrm{MgCl}_{2} \cdot 6 \mathrm{H}_{2} \mathrm{O} 35.5$. The degree of mineralization of the mineralized water was $4614.6 \mathrm{mg} / \mathrm{L}$.

Preparation of simulated ASP flooding produced water. The simulated ASP flooding produced water with a polymer (HPAM) concentration of $400 \mathrm{mg} / \mathrm{L}$, surfactant (ORS-41) concentration of $200 \mathrm{mg} / \mathrm{L}$, and alkali $(\mathrm{NaOH})$ concentration of $800 \mathrm{mg} / \mathrm{L}$.

Treated with xylene, the $1 \%$ demulsifier was used as a solvent. The demulsifier solution was added into the produced water, stirred at a speed of $200 \mathrm{r} / \mathrm{min}$ for $2 \mathrm{~min}$ and settled in the $45^{\circ} \mathrm{C}$ water bath for $4 \mathrm{~h}$. The demulsifier, ZY, was a compound of DYRPR-1625 and DYRPR-1870 at a ratio of 3:1.

The flocculent was added into the produced water, stirred for $2 \mathrm{~min}$ at $200 \mathrm{r} / \mathrm{min}$ and settled in the $45^{\circ} \mathrm{C}$ water bath for $4 \mathrm{~h}$. The flocculent, WS, was a compound of CPAM and D2N-1650 at a ratio of $3: 1$.

Interfacial tension, Zeta potential and oil droplet size were measured after adding demulsifier and flocculent.

\subsection{Experimental Methods}

The experimental methods for the preparation of simulated ASP flooding produced water, determination of the interfacial tension, Zeta potential, oil droplet size and observation of the microscopic morphology of oil droplets were as follows:

Preparation of simulated ASP flooding produced water. The mineralized water was used to prepare simulated produced water from ASP flooding in the lab and the process is as follows: $200 \mathrm{~g}$ of mineralized water with $0.1 \%$ surfactant and $200 \mathrm{~g}$ of crude oil were added to a $500 \mathrm{~mL}$ jar. The mixture was then heated to $45{ }^{\circ} \mathrm{C}$ in a water bath for $60 \mathrm{~min}$. Then, the mixture was emulsified for $5 \mathrm{~min}$ at 20,000 rpm with a T25 emulsifier (IKA Company, Guangzhou, China) to obtain a 50\% oil-water mixture. Next, $0.4 \mathrm{~g}$ of the $50 \%$ oil-in-water emulsion was added to $99.4 \mathrm{~mL}$ mineralized water with different concentrations of oil displacement agents, and the mineralized water was shaken to produce simulated produced water with an oil concentration of $2000 \mathrm{mg} / \mathrm{L}$.

Determination of the oil-water interfacial tension. The oil-water interfacial tension was determined by a spinning drop method and measured by the interfacial tension meter after $60 \mathrm{~min}$. The rotation rate was $8500 \mathrm{r} / \mathrm{min}$. The temperature was $45^{\circ} \mathrm{C}$. The oil-water interfacial tension was obtained by Equation (1):

$$
\gamma=1.233 \times 10^{3} \times \Delta \rho \times(K d s v)^{3}(6000 / S)^{-2},
$$

where the $\Delta \rho$ is density between phases, $\mathrm{kg} / \mathrm{m}^{3} ; K$ is the amplification factor; $d s v$ is droplet width, $\mathrm{m}$; and $S$ is speed, $\mathrm{r} / \mathrm{min}$.

Determination of the Zeta potential. The Zeta potential of the produced water from the ASP flooding was conducted on a Micro electrophoresis apparatus. Firstly, $100 \mathrm{~mL}$ of the simulated produced water with the initial oil concentration of $1000 \mathrm{mg} / \mathrm{L}$ at different demulsifiers and flocculents were allowed to settle for $4 \mathrm{~h}$ at $45^{\circ} \mathrm{C}$. Then, a $5-10 \mathrm{~mL}$ sample was taken out of the jar with a syringe and added to the test utensil of the Micro electrophoresis apparatus for Zeta potential measurement. All measurements were repeated five times. The average values of these readings were reported.

Determination of the oil droplet size. The size of the oil droplets was determined by a mastersizer. All experiments were repeated for $3 \sim 5$ times. The average values of these readings were reported.

Micrograph observations. A drop of produced water was placed on a glass holder held on the platform of a biological microscope and then observed and recorded on a camera. The magnification used was $10 \times 40$. 


\section{Results}

\subsection{The Effect of Demulsifier on Interfacial Tension}

The simulated ASP flooding produced water with $400 \mathrm{mg} / \mathrm{L}$ of the polymer concentration, $200 \mathrm{mg} / \mathrm{L}$ of the surfactant concentration and $800 \mathrm{mg} / \mathrm{L}$ of the $\mathrm{NaOH}$ concentration was prepared and settled in a $45^{\circ} \mathrm{C}$ water bath for $4 \mathrm{~h}$ to study the effect on oil-water interfacial tension in Figure 1. For the emulsion of ASP flooding produced water without adding a demulsifier, the effect of $\mathrm{NaOH}$ on interfacial tension of the system was mainly achieved by the surface-active components formed by the reaction with the acidic components and it had no obvious influence by itself on the interfacial tension. Surfactants had a great influence on the interfacial tension of the system, while the polymer had no effect on the interfacial tension. After adding the demulsifier, it can be observed that the demulsifier can reduce the oil-water interfacial tension. When the dosage of demulsifier increased from 0 to $100 \mathrm{mg} / \mathrm{L}$, the interfacial tension of oil-water decreased from $4.425 \mathrm{mN} / \mathrm{m}$ to $1.325 \mathrm{mN} / \mathrm{m}$, and then stabilized even with further addition from $100 \mathrm{mg} / \mathrm{L}$ to $200 \mathrm{mg} / \mathrm{L}$. When the dosage exceeded $200 \mathrm{mg} / \mathrm{L}$, the interfacial tension began to increase gradually. This is due to the fact that the very active demulsifier molecules can adsorb to the oil-water interface, thus reducing the oil-water interfacial tension. The adsorption of demulsifier molecules on the oil-water interface increased gradually with the increasing dosage of demulsifier. When the concentration reached $100 \mathrm{mg} / \mathrm{L}$, the adsorption of demulsifier molecules on the interface reached saturation. Therefore, the oil-water interfacial tension decreased in concentration when the concentration of demulsifier further increased. Then, when the concentration of the demulsifier was higher than its critical micelle concentration (CMC), the demulsifier molecules began to aggregate into clusters to form micelles which caused the oil-water interfacial tension. In this case, the effect of demulsification and stabilization was reduced.

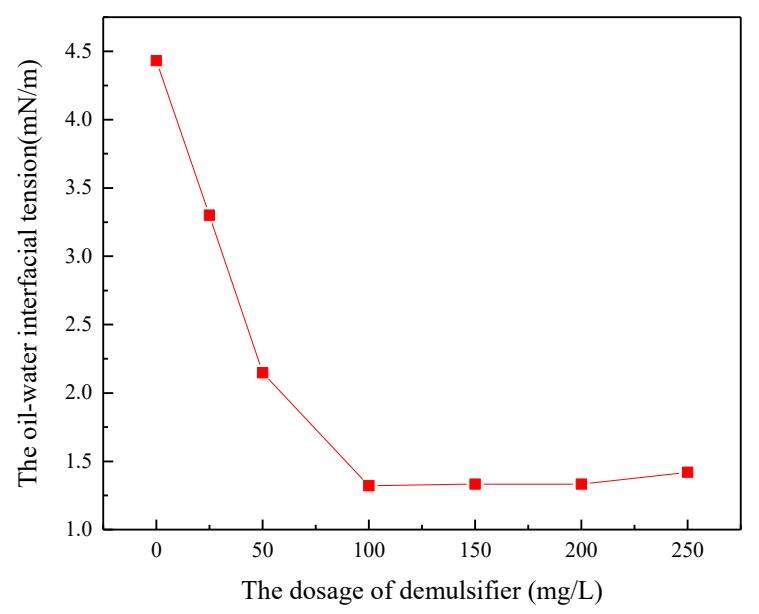

Figure 1. The effect of demulsifier on interfacial tension.

\subsection{The Effect of Demulsifier on Zeta Potential}

The simulated ASP system with $400 \mathrm{mg} / \mathrm{L}$ of the polymer, $800 \mathrm{mg} / \mathrm{L}$ of $\mathrm{NaOH}$ concentration and $0 \sim 600 \mathrm{mg} / \mathrm{L}$ of the surfactant concentrations were prepared. Then, $100 \mathrm{mg} / \mathrm{L}$ of demulsifier ZY was added into the produced water. The ASP system was settled in a $45{ }^{\circ} \mathrm{C}$ water bath for $4 \mathrm{~h}$ to study the effect of the demulsifier on the Zeta of potential surfactants with different concentrations, as shown in Figure 2. For the emulsion of ASP flooding produced water without adding demulsifier, the surfactants were absorbed onto the oil droplets with its non-polar head and polar head group extending in water. The Zeta potential on the surface of the oil droplet decreases quickly because the negative charges on the surface of the oil droplet increased. $\mathrm{NaOH}$ reacted with acidic components of crude oil and produced some surface-active components which adsorbed on the surface of oil droplets to reduce the Zeta potential. With increasing $\mathrm{NaOH}$, the acid components were reacted completely. 
The electric double layer was compressed by the $\mathrm{Na}^{+}$at the oil-water interface, resulting in the Zeta potential increasing on the surface of the oil droplet. The Zeta potential increased as a result of the above two combined effects. The polymer had a limited effect on the Zeta potential and stability of the system because of its low surface activity. After adding demulsifier, the surfactant can significantly improve the stability of the system. A higher concentration of the surfactant results in better stability of the system [32,33]. Compared to the system with no demulsifier, with $100 \mathrm{mg} / \mathrm{L}$ of demulsifier the absolute value of the Zeta potential on the surface of oil droplets decreased significantly at the same surfactant concentration and the stability of the system was changed from stable to unstable. The Zeta potential of the oil droplets changed from $-41.234 \mathrm{mV}$ to $-15.547 \mathrm{mV}$ because the $100 \mathrm{mg} / \mathrm{L}$ of demulsifier was added when the surfactant concentration is 0 . The Zeta potential of the oil droplet was $62.3 \%$. The Zeta potential of the oil droplet was changed from $-67.125 \mathrm{mV}$ to $-30.625 \mathrm{mV}$ when $100 \mathrm{mg} / \mathrm{L}$ of demulsifier was added to $200 \mathrm{mg} / \mathrm{L}$ of the surfactant solution. The absolute value of the Zeta potential of the oil droplet changed from $54.9 \%$ to $51.8 \%$ when the concentration of surfactant increased to $400 \mathrm{mg} / \mathrm{L}$, while the absolute value of Zeta potential was stabilized with increasing surfactant concentration. The effect of demulsifier on the Zeta potential of oil droplets decreases gradually with increasing surfactant concentration.

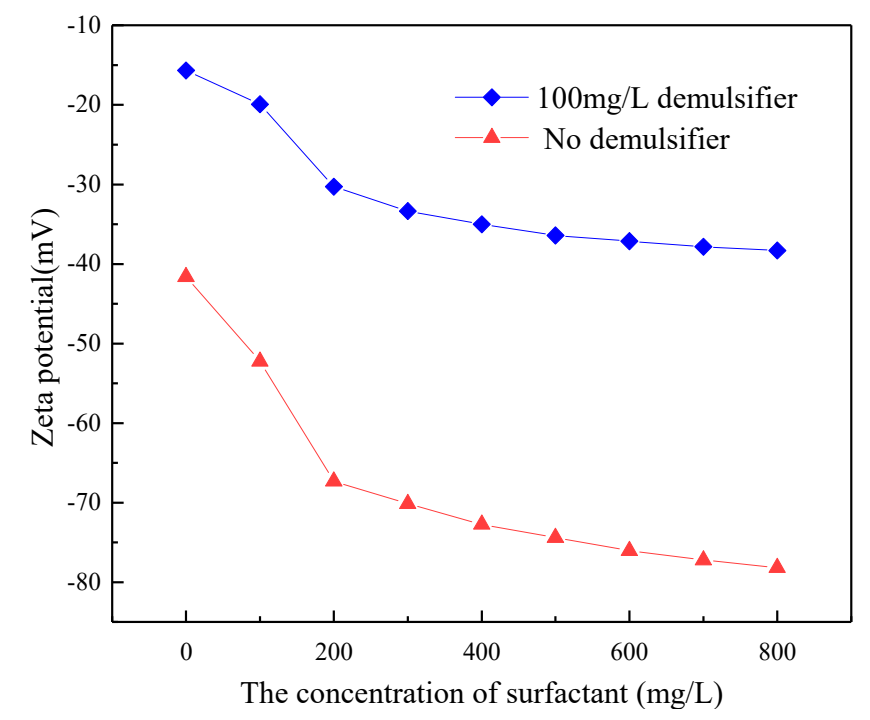

Figure 2. The effect of demulsifier on Zeta potential.

\subsection{The Effect of Demulsifier on the Size of Oil Droplets}

The simulated ASP system with $400 \mathrm{mg} / \mathrm{L}$ of the polymer concentration, $800 \mathrm{mg} / \mathrm{L}$ of $\mathrm{NaOH}$ and $200 \mathrm{mg} / \mathrm{L}$ of the surfactant were prepared. Then, $100 \mathrm{mg} / \mathrm{L}$ of demulsifier $\mathrm{ZY}$ was added into the produced water. The ASP system was settled in a $45^{\circ} \mathrm{C}$ water bath for $2 \mathrm{~h}$ to study the effect of the demulsifier on the size of the oil droplet, as shown in Figure 3. For the emulsion of ASP flooding produced water without adding demulsifier, $\mathrm{NaOH}$ and surfactant prevented oil droplets from coalescing but the polymer helped the oil droplets to coalesce. This is because the $\mathrm{NaOH}$ can react with the acidic components of crude oil and produce some surface-active components. Hence the oil-water interfacial properties changed, which can cause the oil droplets to become more stable. The size of oil droplets decreased with increasing surfactant concentration, which was due to the surfactant increasing the Zeta potential on the surface of the oil droplets and the electrostatic repulsion between oil droplets, resulting in a reduced probability of collision between oil droplets. The polymer had a dual function on the size of the oil droplet. On one hand, the polymer molecule had a bridging and flocculation effect for low polymer concentrations and compressed the double electric layer on the surface of the droplets, which is helpful for the aggregation and coalescence of oil droplets. On the other hand, the polymer molecules covered the surface of the oil droplets creating a steric hindrance 
effect with a high concentration, which was not conducive to the coalescence of oil droplets. After adding demulsifier, the demulsifier molecules adsorbed onto the surface of the oil droplets, resulting in a weakening of the steric hindrance effect of the polymer molecules. Therefore, the polymer molecules in the produced water were beneficial in the separation of emulsions. The demulsifier can significantly increase the median diameter of oil droplets. The median diameter of oil droplets increased from $4.02 \mu \mathrm{m}$ to $4.40 \mu \mathrm{m}$ when settled for $4 \mathrm{~h}$ without a demulsifier. The small increase of oil droplets indicated that the ASP flooding produced water was very stable. However, when settled for $2 \mathrm{~h}$ with added demulsifier $Z Y$, the median diameter of oil droplets increased from $4.02 \mu \mathrm{m}$ to $30.54 \mu \mathrm{m}$. The significant increase in the median diameter of oil droplets showed that the oil droplets in the ASP flooding produced water had become unstable after adding demulsifier. In order to further study the effect of demulsifier on the size of oil droplets, the shapes of oil droplets in the simulated produced water in different conditions were investigated with a microscope. The results are shown in Figure 4. The magnification used was $10 \times 40$. The size of the oil droplets was basically stable without demulsifier and settling for $2 \mathrm{~h}$. The size of the oil droplets increased significantly after adding demulsifier and settled for $60 \mathrm{~min}$. By increasing the settling time, the size of oil droplets increased gradually.

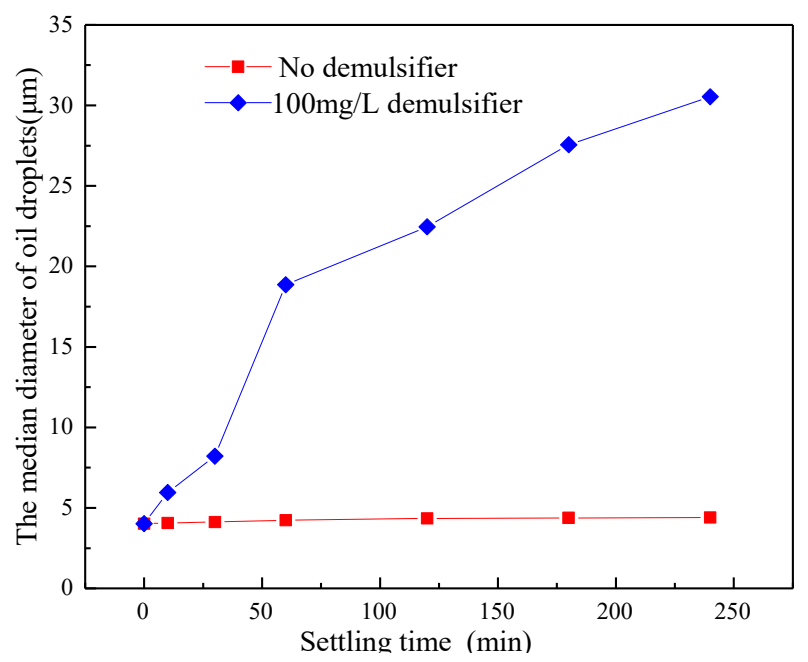

Figure 3. The effect of demulsifier on the median diameter of oil droplets.

By summarizing the above experimental results, the interaction of ASP with the added demulsifiers can be found. The effect of $\mathrm{NaOH}$ on the stability of produced water was mainly achieved by the surface-active components formed from the reaction with the acidic components of crude oil, which produces some surface-active components which adsorbed on the surface of the oil droplets. During demulsification, the demulsifier molecules can be adsorbed onto the oil droplets, replacing the surfactant absorbed on the surface of oil droplets and resulting in a weakening of the steric hindrance effect of the polymer molecules. The processes reduced interfacial tension and weakened interfacial film strength, so that the stability of oil droplets was decreased. At the same time, the demulsifier can also neutralize the negative charge on the surface of the oil droplet, reducing the electrostatic repulsion between the oil droplets and aiding the accumulation of oil droplets. 


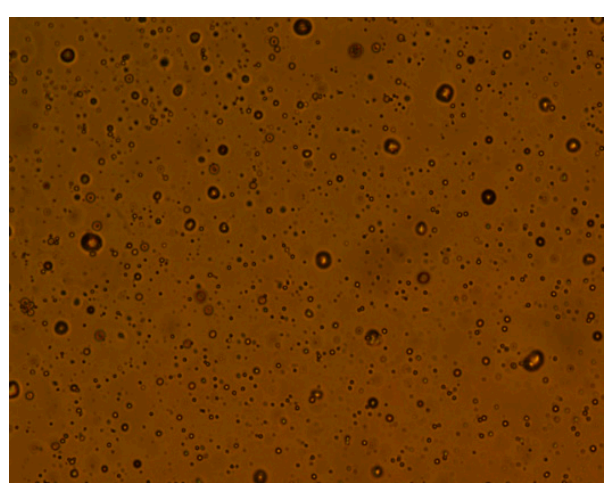

(a)

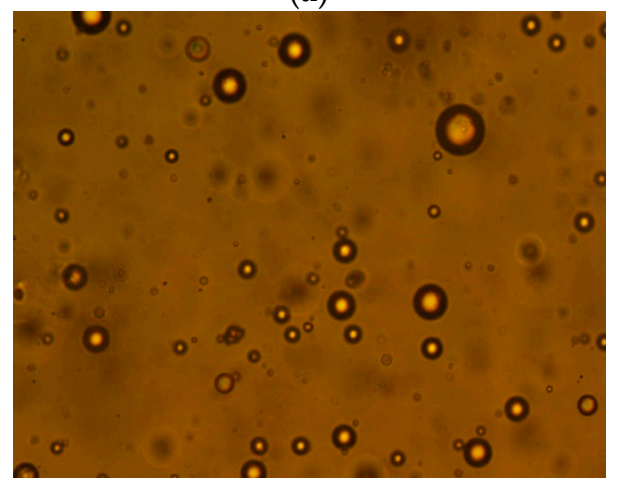

(c)

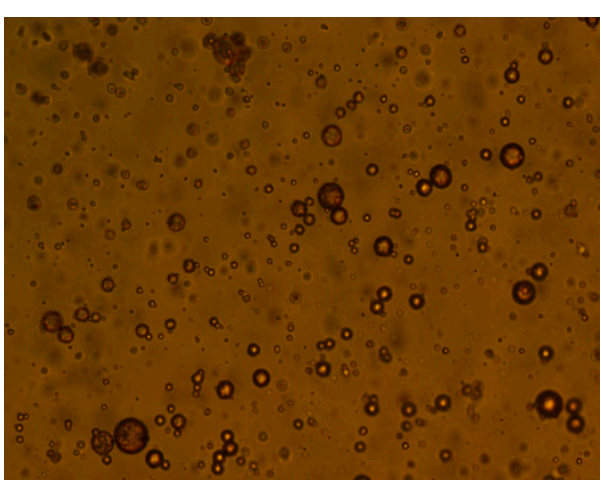

(b)

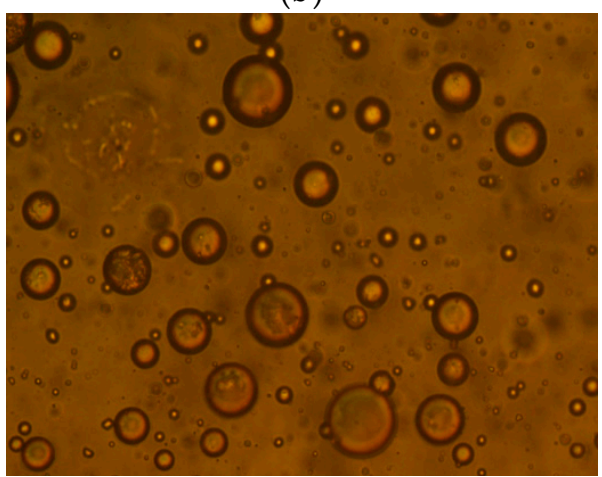

(d)

Figure 4. The effect of demulsifier on the size of oil droplets. (a) Settlement without demulsifier for $0 \mathrm{~min}$, (b) settlement without demulsifier for $120 \mathrm{~min}$, (c) settlement with demulsifier for $0 \mathrm{~min}$, (d) settlement with demulsifier for $120 \mathrm{~min}$.

\subsection{The Effect of Flocculant on Interfacial Tension}

The simulated ASP flooding produced water with $400 \mathrm{mg} / \mathrm{L}$ of polymer, $200 \mathrm{mg} / \mathrm{L}$ of surfactant concentration and $800 \mathrm{mg} / \mathrm{L}$ of $\mathrm{NaOH}$ concentration was prepared and settled in a water bath temperature of $45^{\circ} \mathrm{C}$ for $4 \mathrm{~h}$ to study the effect of flocculant WS on oil-water interfacial tension. The effects of CPAM and D2N-1650 on oil-water interfacial tension were studied respectively under the same experimental conditions, as shown in Figure 5. The flocculant WS can increase the oil-water interfacial tension. When the concentration of flocculant increased from 0 to $70 \mathrm{mg} / \mathrm{L}$, the interfacial tension of oil-water increased from $4.425 \mathrm{mN} / \mathrm{m}$ to $6.153 \mathrm{mN} / \mathrm{m}$. The flocculant WS can only slightly increase oil-water interfacial tension, and its ability to do so is a result of the CPAM in the flocculant WS. With increasing concentration of the flocculant WS, the concentration of polyacrylamide in the system increased. Therefore, the viscosity of the system increased and the transportation and adsorption of surfactant on the oil-water interface was influenced. Thus, the amount of surfactant reaching the oil-water interface decreased, resulting in an increase in oil-water interfacial tension. However, the hindrance was weak, so the increase of oil-water interfacial tension was limited. The flocculant CPAM had no effect on the oil-water interfacial tension [34]. Compared to flocculant D2N-1650, the flocculent CPAM played a larger role in reducing the oil-water interfacial tension. Finally, the concentration of flocculant WS can increase the oil-water interfacial tension.

\subsection{The Effect of Flocculant on Zeta Potential}

The simulated ASP flooding produced water with $400 \mathrm{mg} / \mathrm{L}$ of polymer, $800 \mathrm{mg} / \mathrm{L}$ of $\mathrm{NaOH}$ and $200 \mathrm{mg} / \mathrm{L}$ of the surfactant was prepared. The flocculant WS was added into the produced water and both were settled in a water bath at a temperature of $45^{\circ} \mathrm{C}$ for $4 \mathrm{~h}$ to study the effect of the flocculant on Zeta potential for the ASP flooding produced water. The effects of CPAM and D2N-1650 on Zeta potential were studied respectively under the same experimental conditions, as shown in 
Figure 6. The flocculant CPAM and D2N-1650 can reduce the absolute value of the Zeta potential individually, however the interaction of the two flocculants can reduce the absolute value of Zeta potential even further. A large number of positive charges on the molecular chain from the flocculant CPAM neutralized the negative charge on the surface of the oil droplet. Then the absolute value of Zeta potential on the droplet surface decreased greatly. The flocculant D2N-1650 did not have positive charges. It can only bind the oil droplets together to produce precipitation through "adsorption bridging". Therefore, the influence of the flocculant D2N-1650 on the Zeta potential was limited.

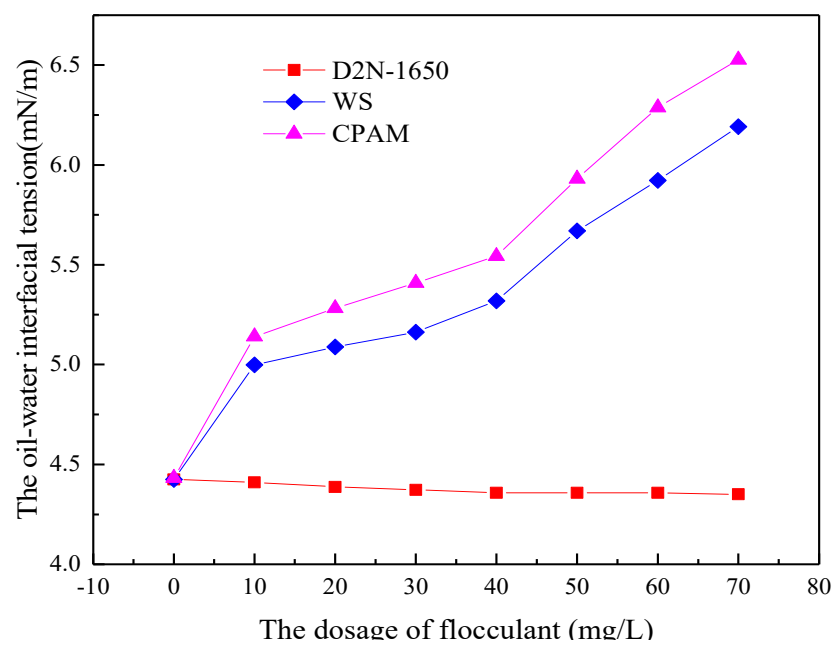

Figure 5. The effect of flocculant on interfacial tension.

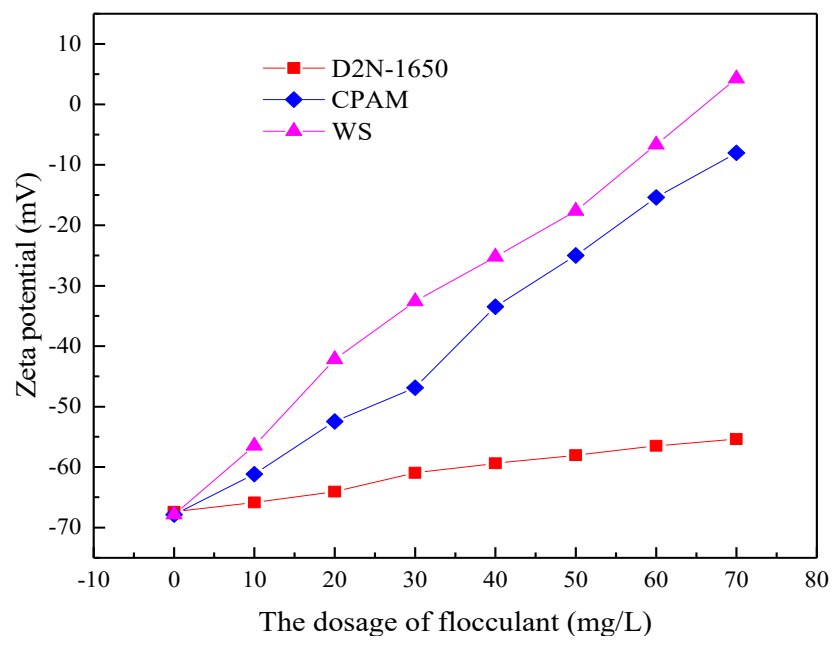

Figure 6. The effect of flocculant on Zeta potential.

\subsection{The Effect of Flocculant on the Size of Oil Droplets}

The simulated ASP flooding produced water with $400 \mathrm{mg} / \mathrm{L}$ of polymer, $800 \mathrm{mg} / \mathrm{L}$ of $\mathrm{NaOH}$ and $200 \mathrm{mg} / \mathrm{L}$ of the surfactant was prepared. Then, $60 \mathrm{mg} / \mathrm{L}$ flocculant WS was added into the produced water and settled in a $45{ }^{\circ} \mathrm{C}$ water bath for $2 \mathrm{~h}$ to study the effect of flocculant on oil droplet median diameter, as shown in Figures 7 and 8. The magnification used to produce Figure 8 was $10 \times 40$. There is an obvious effect of the flocculant increasing the median diameter of oil droplets. The median diameter of oil droplets increased when settled for $2 \mathrm{~h}$ without flocculant. The limited increase indicated that the ASP flooding produced water was very stable. However, the median diameter of oil droplets increased from $4.02 \mu \mathrm{m}$ to $20.15 \mu \mathrm{m}$ when settled for $2 \mathrm{~h}$ with added flocculant into the system. The significant increase of the median diameter of oil droplets indicated that the oil droplets in the ASP flooding produced water had become unstable after adding flocculant. However, when 
compared with adding demulsifier ZY, the effect of flocculant WS was relatively small. In order to further investigate the effect of demulsifier on the size of oil droplets, the shapes of oil droplets in the simulated produced water at different conditions were studied with a microscope, the results of which are shown in Figure 8. The size of oil droplets in the simulated produced water without flocculant was basically unchanged after settlement for $2 \mathrm{~h}$. The size of oil droplets increased significantly after adding flocculant for settlement for $60 \mathrm{~min}$. With an increase in settling time, the size of oil droplets increased gradually.

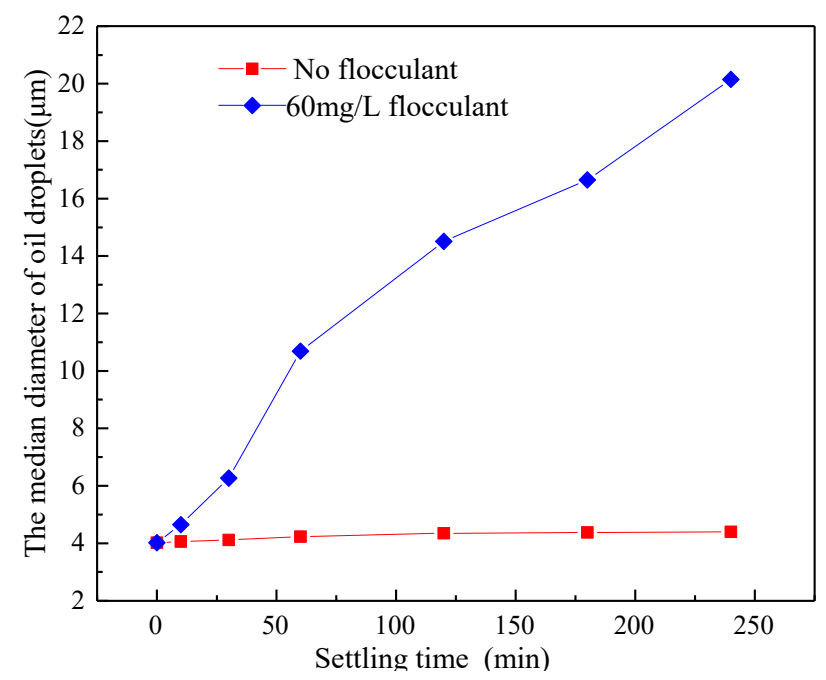

Figure 7. The effect of flocculant on the median diameter of oil droplets.

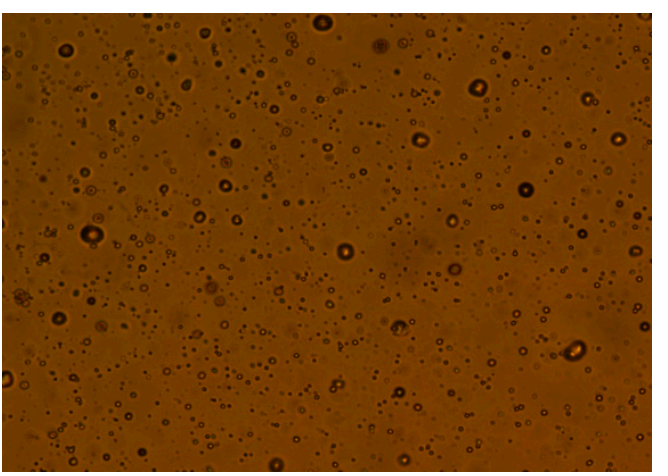

(a)

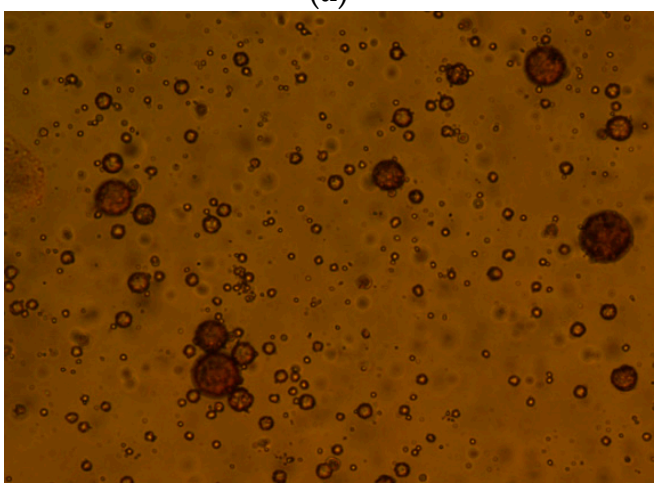

(c)

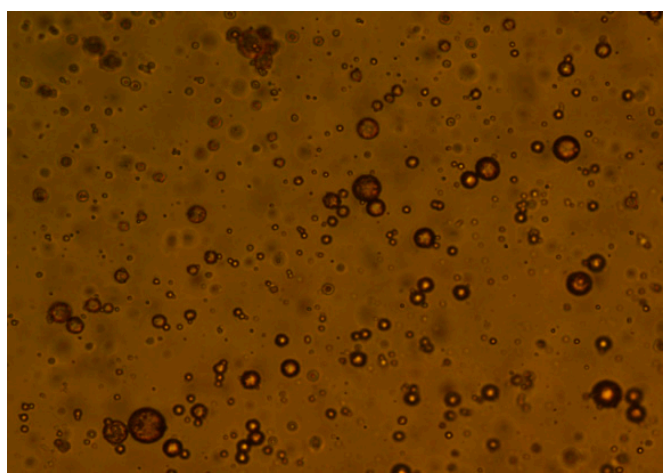

(b)

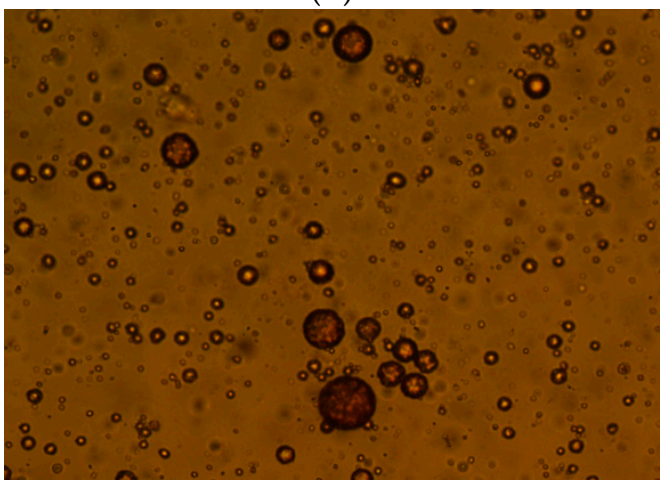

(d)

Figure 8. The effect of flocculant on the size of oil droplet. (a) Settlement without flocculant for $0 \mathrm{~min}$, (b) settlement without flocculant for $120 \mathrm{~min}$, (c) settlement with flocculant for $0 \mathrm{~min}$, (d) settlement with flocculant for $120 \mathrm{~min}$. 


\section{Demulsification-Flocculation Mechanism of Oil-Water Emulsion}

After comparison and analysis of the theoretical and experimental results, the mechanism of demulsification and flocculation was summarized, as shown in Figure 9. The demulsifier molecules can be adsorbed onto the oil droplets, replacing the surfactant absorbed on the surface of oil droplet, to reduce the interfacial tension, and weaken interfacial film strength, so that the stability of oil droplets decreased. At the same time, the demulsifier can also neutralize the negative charge on the surface of the oil droplet, reducing the electrostatic repulsion between oil droplets, allowing the accumulation of oil droplets. The flocculant after demulsification of oil droplets by charge neutralization, adsorption bridging and sweep function together, so that the oil droplets form aggregates, then the synthetic action of the demulsifier and the flocculant causes the oil droplet film to break up and oil droplet coalescence occurs, so as to achieve the purpose of oil-water separation.

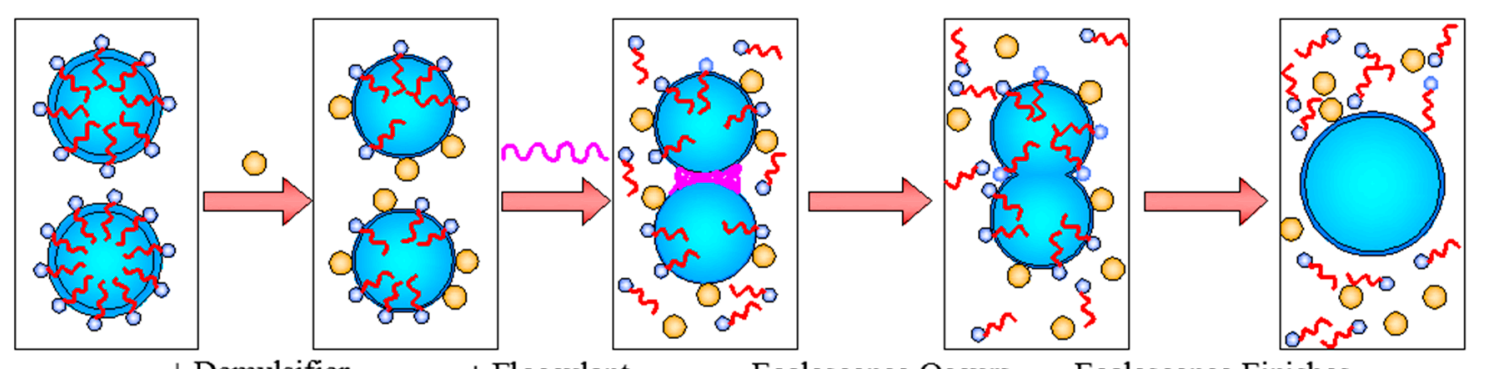

Figure 9. Demulsification-Flocculation mechanism.

\section{Conclusion}

In this paper, we studied the demulsification-flocculation mechanism of produced water from ASP flooding by considering oil-water interfacial tension, Zeta potential and the size of oil droplets of produced water with added demulsifier and flocculent through laboratory experiments.

We demonstrated that the demulsification-flocculation mechanism is feasible and can be applied to the produced water from ASP flooding. The demulsifier molecules can be adsorbed onto the oil droplets and replace the surfactant absorbed on the surface of oil droplets, thereby reducing the interfacial tension and weakening the interfacial film strength. The demulsifier can also neutralize the negative charge on the surface of oil droplets and reduce the electrostatic repulsion between them, which is beneficial in the accumulation of oil droplets. The flocculent after demulsification of oil droplets by charge neutralization, adsorption bridging, and sweep function together. Therefore, the oil droplets form aggregates and the synthetic action of the demulsifier. The flocculent causes the oil drop film to break and then the oil droplets coalesce, resulting in oil water separation.

Author Contributions: Conceptualization, B.H.; Methodology, Formal Analysis, Investigation and WritingOriginal Draft Preparation, B.H., X.L. and W.Z.; Writing-Review \& Editing, Supervision and Project Administration, C.F.; Writing-Review \& Editing, Y.W. \& S.F.

Acknowledgments: The authors gratefully acknowledge the financial support by National Natural Science Foundation of China (51804077); Excellent Scientific Research Talent Cultivation Fund of Northeast Petroleum University (SJQHB201803).

Conflicts of Interest: The authors declare no conflict of interest.

\section{References}

1. Zhong, H.; Li, Y.; Zhang, W.; Yin, H.; Lu, J.; Guo, D. Microflow mechanism of oil displacement by viscoelastic hydrophobically associating water-soluble polymers in enhanced oil recovery. Polymers 2018, 10, 628. [CrossRef]

2. Zhao, Y.; Wu, J.; Shi, F. Evaluation of the Effect of Microbial Combination Flooding. Adv. Petrol. Explor. Dev. 2016, 11, 2. 
3. Wei, B.; Li, Q.; Jin, F.; Li, H.; Wang, C. The Potential of a Novel Nano-fluid in Enhancing Oil Recovery. Energy Fuels 2016, 30, 2882-2891. [CrossRef]

4. Wei, B.; Li, H.; Li, Q.; Lu, L.; Li, Y.; Pu, W.; Wen, Y. Investigation of Synergism between Surface-grafted Nano-cellulose and Surfactants in Stabilized Foam Injection Process. Fuel 2017, 207, 352-364. [CrossRef]

5. Nedjhioui, M.; Moulai-Mostefa, N.; Morsli, A. Combined effects of polymer/surfactant/oil/alkali on physical chemical properties. Desalination 2005, 185, 543-550. [CrossRef]

6. Liu, Y.; Wang, Z.H.; Zhuge, X.L. An environmentally-friendly method for disposal of the ASP flooding produced water. In Proceedings of the SPE Arctic and Extreme Environments Technical Conference and Exhibition, Moscow, Russia, 15-17 October 2013.

7. Nguyen, D.; Sadeghi, N. Stable emulsion and demulsification in chemical EOR flooding: Challenges and best practices. In Proceedings of the SPE EOR Conference at Oil and Gas West Asia, Muscat, Oman, 16-18 April 2012.

8. Yang, X.; Liao, G.Z.; Han, P.H.; Yang, Z.Y.; Yao, Y.N. An Extended field Test Study on Alkaline-SurfactantPolymer Flooding in Beiyiduanxi of Daqing Oilfield. In Proceedings of the SPE Asia Pacific Oil and Gas Conference and Exhibition, Jakarta, Indonesia, 9-11 September 2003.

9. Igunnu, E.T.; Chen, G.Z. Produced water treatment technologies. Inter. J. Low-Carbon Technol. 2014, 9, $157-177$. [CrossRef]

10. Zhang, X.J.; Ji, W.; Wang, B.H. Study on the treatment technology of oilfield produced water. Indust. Safety Environ. Protec. 2007, 33, 13-16.

11. Li, J.X.; Liu, Y.; Wu, D.; Meng, X.C.; Zhao, F.L. Synergistic Effects of Alkaline, Surfactant, and Polymer on the Emulsification and Destabilization of Oil-in-Water Crude Oil Emulsion Produced by AlkalineSurfactant-Polymer Flooding. Petrol. Sci. Technol. 2013, 31, 399-407. [CrossRef]

12. Kudaibergenov, S.; Akhmedzhanov, T.K.; Zhappasbayev, B.Z.; Gussenov, I.S.; Shakhvorostov, A.V. Laboratory Study of ASP Flooding for Viscous Oil. Inter. J. Chem. Sci. 2015, 13, 2017-2025.

13. Khambharatana, F.; Thomas, S.; Ali, S. Macroemulsion Rheology and Drop Capture Mechanism During Flow in Porous Media. In Proceedings of the SPE International Oil and Gas Conference and Exhibition in China, Society of Petroleum Engineers, Beijing, China, 2-6 November 1998.

14. Fatemeh, G.; Sohrab, Z. A Comprehensive Review on Emulsions and Emulsion Stability in Chemical and Energy Industries. Can. J. Chem. Eng. 2019, 97, 281-309.

15. Wang, J.; Song, C.; Li, C. Effect of ASP composition on the emulsion-stabilizing properties of simulativeproduced liquid by ASP flooding. J. China Univ. Petrol. 2016, 40, 146-154.

16. Zhang, R.; Liang, C.; Wu, D.; Deng, S. Characterization and demulsification of produced liquid from weak base ASP flooding. Colloids Surf. A 2006, 290, 164-171. [CrossRef]

17. Demirbas, A.; Bamufleh, H.; Edris, G.; Alalayah, W.M. Treatment of contaminated wastewater. Petrol. Sci. Technol. 2017, 35, 883-889. [CrossRef]

18. Hanafy, M.; Nabih, H. Treatment of oily wastewater using dissolved air flotation technique. Energy Sources Part A 2007, 29, 143-159. [CrossRef]

19. Ran, J.C.; Liu, J.T.; Zhang, C.J.; Wang, D.Y.; Li, X.B. Experimental investigation and modeling of flotation column for treatment of oily wastewater. Inter. J. Mining Sci. Technol. 2013, 23, 665-668. [CrossRef]

20. Yang, F.; Tchoukov, P.; Qiao, P.Q.; Ma, X.; Pensini, E.; Dabros, T.; Czarnecki, J.; Xu, Z. Studying demulsification mechanisms of water-in-crude oil emulsions using a modified thin liquid film technique. Colloids Surf. A 2018, 540, 215-223. [CrossRef]

21. Rajak, V.K.; Singh, I.; Kumar, A.; Mandal, A. Optimization of separation of oil from oil-in-water emulsion by demulsification using different demulsifiers. Petrol. Sci. Technol. 2016, 34, 1026-1032. [CrossRef]

22. Dickhout, J.M.; Moreno, Y.; Biesheuvel, P.M.; Boels, L.; Lanunertink, R.G.H. Produced water treatment by membranes: A review from a colloidal perspective. J. Colloid Interf. Sci. 2017, 487, 523-534. [CrossRef] [PubMed]

23. Rajak, V.K.; Relish, K.K.; Kumar, S.; Mandal, A. Mechanism and Kinetics of Separation of Oil from Oil-in-Water Emulsion by Air Flotation. Petrol. Sci. Technol. 2015, 33, 1861-1868. [CrossRef]

24. Rajak, V.K.; Kumar, S.; Thombre, N.V.; Mandal, A. Synthesis of activated charcoal from saw-dust and characterization for adsorptive separation of oil from oil-in-water emulsion. Chem. Eng. Commun. 2018, 205, 897-913. [CrossRef] 
25. Foulds, B. Fixed-Media Biotechnology Provides Efficient Wastewater Treatment \& Quality Effluent. Plant Eng. 2013, 6, 6-7.

26. Deng, S.B.; Bai, R.B.; Chen, J.P. Effects of alkaline/surfactant/polymer on stability of oil droplets in produced water from ASP flooding. Colloids Surf. A 2002, 2002, 275-284. [CrossRef]

27. Deng, S.B.; Yu, G.; Jiang, Z.P. Destabilization of oil droplets in produced water from ASP flooding. Colloids Surf. A 2005, 252, 113-119. [CrossRef]

28. Wang, B.; Wu, T.; Li, Y.J. The effects of oil displacement agents on the stability of water produced from ASP (alkaline/surfactant/polymer) flooding. Colloids Surf. A 2011, 379, 121-126. [CrossRef]

29. Gao, R.T.; Li, F.; Li, Y.J. Effective removal of emulsified oil from oily wastewater using in-situ generated metallic hydroxides from leaching solution of white mud. Chem. Eng. J. 2017, 309, 513-521. [CrossRef]

30. Zhang, B.; Yu, S.L.; Zhu, Y.B. Application of polytetrafluoroethylene (PTFE) flat membrane for the treatment of pre-treated ASP flooding produced water in a Daqing oilfield. RSC Adv. 2016, 6, 62411-62419. [CrossRef]

31. Miao, L.; Li, F.; Sun, D.J. Interfacial and electrokinetic properties of asphaltenes and alkali/surfactant/ polymer in produced water system. J. Petrol. Sci. Eng. 2015, 133, 18-28. [CrossRef]

32. Li, X.H.; Kerstern, S.R.A.; Schuur, B. Efficiency and mechanism of demulsification of oil-in-water emulsions using ionic liquids. Energy Fuels 2016, 30, 7622-7628. [CrossRef]

33. Jiang, H.; Sun, N.; Wang, J.; Tong, J. Demulsification efficiency of heavy oil-in-water emulsion stabilized by organic alkali and compound surfactants. Oilfield Chem. 2016, 33, 338-344.

34. Zhang, Z. The flocculation mechanism and treatment of oily wastewater by flocculation. Water Sci. Technol. 2017, 76, 2630-2637. [CrossRef] [PubMed]

(C) 2019 by the authors. Licensee MDPI, Basel, Switzerland. This article is an open access article distributed under the terms and conditions of the Creative Commons Attribution (CC BY) license (http://creativecommons.org/licenses/by/4.0/). 